\title{
RISK OF SPREADING DELTA CORONAVIRUS TO OPERATING ROOM PERSONNEL AFTER COVID-19 VACCINATION
}

\author{
Amirmohammad Merajikhah ${ }^{1}$, Atefeh Beigi-Khoozani ${ }^{2}$, Mahdieh Soleimani ${ }^{3}$ \\ 'Department of Operating Room, Sabzevar University of Medical Sciences, Razavi Khorasan, Iran \\ ${ }^{2}$ Department of Operating Room, Iran University of Medical Sciences, Tehran, Iran \\ ${ }^{3}$ Department of Operating Room, Maragheh University of Medical Science, East Azerbaijan, Iran
}

KEY WORDS: deltacoronavirus, perioperative team, operation room, vaccination

Disaster Emerg Med J 2021; 6(4): 206-207

\section{Dear Editor,}

porcine Delta Coronavirus (PDCoV), is a virus of the corona family of porcine enteropathogenic virus that was recently discovered and has a global pandemic. Therefore, effective strategies to prevent or treat infection remain unattainable [1]. It should be noted that the delta virus can increase the risk of admission to the hospital [2] and it seems that the rate of hospitalization due to this infection is up to twice as much as the previous infection [2] and increasing the hospital admission rate increases the pressure on the already exhausted health system and can put pressure on it [3]. Even a small increase in admissions affects admission capacity and can jeopardize efforts to improve. Admission of patients infected with delta coronavirus in hospitals is currently increasing, and this has affected the capacity of hospitals [2], which subsequently increases the admission of patients in the operating rooms. The importance of this issue becomes clear when patients with delta coronavirus admitted to operating rooms may be identified if they are candidates for elective surgery; however, emergency patients admitted to operating rooms can be infected with the delta variant of the coronavirus and can easily transmit this dangerous variant of the coronavirus to operating room staff.
Another concern is that COVID-19 vaccines are ineffective against the delta variant, especially after a single dose; For example, the Pfizer vaccine is $88 \%$ effective and the Oxford AstraZeneca vaccine is $60 \%$ effective against the delta type two weeks after the second dose [4]. Therefore, it can be acknowledged that even the psychological effects of COVID-19 vaccination can be altered and that stress from the delta coronavirus epidemic can reduce the performance of COVID-19 vaccines, leaving operating room staff at greater risk of infection of delta coronavirus. Current data suggest that the virus is highly targeted to human airway cells, meaning that it increases the production of the virus in the infected person, and therefore patients may transmit more virus into the air [2]. Therefore, during admission as well as intubation, operating room personnel are more likely to be contaminated by the Delta variant. According to the available evidence, the coronavirus delta variant has the potential to spread more and increase the admission of patients in hospitals, and on the other hand, the probability of admitting carriers to emergency surgeries in operating rooms increases. Therefore, more preventive strategies should be adopted in the operating rooms despite vaccination for COVID-19.

ADDRESS FOR CORRESPONDENCE:

Atefeh Beigi-Khoozani, Department of Operating Room, Iran University of Medical Sciences, Tehran, Iran e-mail: ati.bgi2016@gmail.com

This article is available in open access under Creative Common Attribution-Non-Commercial-No Derivatives 4.0 International (CC BY-NC-ND 4.0) license, allowing to download articles and share them with others as long as they credit the authors and the publisher, but without permission to change them in any way or use them commercially. 


\section{Conflict of interest}

All authors declare no conflict of interest.

\section{REFERENCES}

1. Duan C, Wang J, Liu Yi, et al. Antiviral effects of ergosterol peroxide in a pig model of porcine deltacoronavirus ( $\mathrm{PDCOV}$ ) infection involves modulation of apoptosis and tight junction in the small intestine. Vet Res. 2021; 52(1): 86, doi: 10.1186/s13567-021-00955-5, indexed in Pubmed: 34127062.
2. Mahase E. Delta variant: What is happening with transmission, hospital admissions, and restrictions? BMJ. 2021; 373: n1513, doi: 10.1136/bmj.n1513, indexed in Pubmed: 34130949.

3. Mahase E. Covid-19: Is it safe to lift all restrictions in England from 21 June? BMJ. 2021: n1399, doi: 10.1136/bmj.n1399.

4. lacobucci G. Covid-19: Single vaccine dose is 33\% effective against variant from India, data show. BMJ. 2021; 373: n1346, doi: 10.1136/ bmj.n1346, indexed in Pubmed: 34035039. 